Article

\title{
Tendencies of Residents in Sanjiangyuan National Park to the Optimization of Livelihoods and Conservation of the Natural Reserves
}

\author{
Ting Ma ${ }^{1}$, Kun Xu ${ }^{2}$, Yiming Xing ${ }^{1}$, Hang Shu ${ }^{1}$ and Weiguo Sang ${ }^{1, * \mathbb{D}}$ \\ 1 College of Life and Environmental Sciences, Minzu University of China, No. 27 Zhongguancun Nandajie, \\ Beijing 100081, China; 17400198@muc.edu.cn (T.M.); hmzxym@163.com (Y.X.); sdshuhang@163.com (H.S.) \\ 2 Department of Renewable Resources, Faculty of Agricultural, Life \& Environmental Sciences, University of \\ Alberta, Edmonton, AB T6G 2H1, Canada; kun1@ualberta.ca \\ * Correspondence: swg@muc.edu.cn
}

Received: 7 May 2020; Accepted: 22 June 2020; Published: 24 June 2020

check for updates

\begin{abstract}
Current research on residents' ecological protection behaviors commonly adopts the socio-economic approach at the individual level. Yet, such an approach might ignore the impacts of potential psychological factors on resident behaviors, such as on farmers' willingness and perception to conservation (collectively defined as residents' tendencies in this study). This research analyzed the factors influencing residents' preferences for conservation and livelihood trade-off at the community level in Sanjiangyuan National Park, China. We conclude: First, the factors associated with government funding lead to residents' inclination to trust local government. Subsequently, abundant wealth contributes to the open-mindedness of residents to accept that "changes" are worthy. Second, despite the limited level of education, the fact that residents do not consider terms and conditions of regulations does not hinder recent social and ecological transformation. Third, residents' comparative support for policies and regulations are commonly related to their interests in livelihood and ecological protection, but the support levels differ among different counties due to geographical and social heterogeneities. Collectively, policymakers should realize the importance of residents' tendencies as well as their confidence in local government when planning to optimize social ecological transformation policies with a balance between the compensations given and benefits received.
\end{abstract}

Keywords: optimization of livelihoods and conservation of natural reserve; residents; Sanjiangyuan National Park; tendencies

\section{Introduction}

The Intergovernmental Platform on Biodiversity and Ecosystem Services (IPBES) for science policy aims to bridge science and policy by assessing and integrating all forms of knowledge about biodiversity [1]. Its ambitious goals are interrelated with not only natural sciences but also social and human sciences, as well as indigenous and local knowledge systems. Recent IPBES assessments show that, globally, goals for sustainability are not likely to be achieved without an improved understanding of the feedback relationship between society and ecosystems, while improved effectiveness of governance systems also matters [2]. Sustainability has long been at the heart of the United Nations Member States policies [3]. Of all the effort, natural reserves have been the most prevalent approaches shared by the governments in over 150 countries.

The national park, a primary type of natural reserve, has been playing an important role in China's nature reserve system for nearly 150 years [4]. China's national parks are still in the experimental stage, requiring further construction and following a top-down management model [5]. Among all 
the national parks of China, several of the most significant ones are located along the Three Rivers, whose source is in the central plateau of the Qinghai Tibet Plateau. The Three Rivers' name comes from its three most important rivers in Asia: the Yangtze River, the Yellow River and the Lancang River (Mekong) [6], whose area covers $36.3 \times 10^{6}$ hectares, with an average altitude of $4000 \mathrm{~m}$, and the highest annual altitude of snow reserves [7]. In order to conserve the Sanjiangyuan National Park, the Qinghai Provincial Government established the Sanjiangyuan Provincial Nature Reserve in 2000 and the Qinghai Sanjiangyuan Nature Reserve Administration one year later. In 2003, the state council officially approved the area as a national nature reserve [8]. Accompanied by the ecological civilization system reform, Sanjiangyuan National Park was established as the first national park in China in 2015. Sanjiangyuan National Park has received various sources of government funding demonstrating the strong determination of both the central and local government to protect its ecological conditions. For example, in 2005, the State Council approved the ultimate plan for ecological protection and restoration (EPRP) and designated 7.5 billion yuan (USD 0.92 billion in 2005) for the ecosystem protection and restoration projects there. Although a series of sustainable projects implemented in Sanjiangyuan National Park has achieved some of the main goals, some researchers believe that the management of Sanjiangyuan National Park needs fundamental livelihood transformation due to the increasing living pressure brought by climate change and people's unsustainable needs $[5,9,10]$. In order to fundamentally curb the degradation of the ecosystem, develop the protocols of the conservation work, and improve the livelihoods of local people, the State Council approved the implementation of the "Three River Source National Comprehensive Test and Demonstration Area" (SITDR) in 2011. The ecological construction project and sustainable plan of SITDR not only aims to strengthen the national environmental protection strategy in Sanjiangyuan National Park but also targets at its transformation.

Despite the effort for conservation supported by the State Council, Sanjiangyuan National Park have experienced increasingly severe ecosystem degradation and soil erosion due to climate change and increased the frequency and intensity of human activities in the recent 2 decades [11]. Particularly, the ecological environment in the source area of the Three Rivers is sensitive and fragile. Once the alpine grassland vegetation is disturbed or degraded, it will become difficult to restore [12]. Recently, considerable attention has been paid to this source area in order to control grassland degradation and promote regional sustainable development [13]. To protect the fragile ecological environment of the source area, 22 ecological restoration strategies have been implemented since 2000 [14]. These plans aim to reduce land degradation, alleviate rural poverty with central government support, and promote sustainable economic development, which, in turn, brought enormous social and ecological change sources to Sanjiangyuan National Park [15]. And it is known that environmental restoration policy is helpful to improve the provision of ecosystem services for the entire region. Notably, grassland degradation has been alleviated in the regional nature reserves: net primary production (NPP) increased by $45 \%$, grassland biomass increased by $24.7 \%$ and runoff, providing water resources to downstream areas, and water quality improved [16]. As mentioned above, the long-term social and ecological transformation policies and plans have significantly contributed to maintaining local ecological stability. Collectively, the aims of protecting and improving the local ecological and environmental conditions in Sanjiangyuan National Park were reached after 2 decades since the implementation of the Phase I and Phase II ecological conservation plans. The two major conservation policies embedded in these two phases are ecological compensation and ecological relocation policies, which have had different actual conservational effects and residents' feedback in Sanjiangyuan National Park. Comparing to the relatively successful ecological compensation policy, ecological relocation policy adopted a "one-for-all" management strategy without various relocation plans targeting at residents with different household background and livelihood difficulty. The subsequent problems of the ecological relocation policy were a high dependence on government financial support, a lack of self-sustainability in production and income, nonincreasing happiness of relocated residents, while the local government could not afford to pay the budget for seemingly endless transactions after the 
ecological relocation policy failed [17]. To solve these problems, China aims to establish a protected area system by 2020, which will be improved with added management efficiency to protect a fragile ecosystem. To meet the needs of sustainable natural conservation in Sanjiangyuan National Park, relevant research is critical for policymakers to strengthen sustainability policies when designing follow-up projects.

Many studies focused on the effects of policy and farmers' socio-economic characteristics on their decision making and behaviors using decision making and conservational behaviors using decision making models with descriptive household and livelihood variables. In particular, Cao et al. [17] found that the gender, education, age, location, and net annual income of farmers were closely related with their land-use plan and attitude toward the ecological compensation program. Bo et al. [18] reported a logistic regression model demonstrating that the age of the household respondents, number of family members, cropland area, and the degree of satisfaction toward the compensation were the most significant factors affecting farmers' willingness to preserve the ecological achievements in western China. Other studies also found that the ecological subsidy for conservation, duration of the ecological compensation program, labor in the family, economic income, and distance from the house to land should be considered $[19,20]$. Although previous studies revealed valuable patterns and implications, there still exist three major limitations. First of all, there are significant inconsistencies among the initial factors that have been selected in these studies, which might lead to different conclusions. Secondly, most of these studies are commonly based on the assumption that farmers' behaviors and their intentions are homogeneously positive toward government ecological compensation policies [21]. However, this hypothesis might not be valid in every national park, such as Sanjiangyuan National Park. In fact, Knowler et al. [22] summarized in their meta-analysis that socio-economic characteristics usually exert a negligible effect on farmers' adoption decisions. Thirdly, socio-psychological methods widely used in these studies are insufficient to differentiate farmers' intentions to adopt improved technology [23], conservational behavior [24], a land-use plan [25], climate change adaptation [26], or water conservation [27]. Livelihood and ecology conservation in natural reserves, especially national parks, have been of international concerns on the sustainable ecotourism, conservation and livelihood [28,29]. In particular, there has been a strong focus on identifying and quantifying the economic benefits that local people derive from biodiversity [30,31]. Mbile et al. [32] evaluated Korup National Park's potential links between the communities' livelihood and the long-term management and survival of the park as the important biodiversity conservation zone in Cameroon. Timothy et al. [33] used mixed methodologies to examine the character and incidence of livelihood diversification within communities near Tarangire National Park in northern Tanzania compared to communities far from the park, which offered insight into the underlying mechanisms that shape household-level outcomes such as income and wealth. Despite several studies discussing the linkage between livelihoods and conservation, little has been done to analyze the factors that affect residents' preferences for conservation and livelihood trade-off at the community level [30].

As a matter of fact, researches based on the analysis of variance (ANOVA) method to test residents' intentions and behavioral factors for natural conservation are solid when considering the above limitations of the data and analytics [34]. The ANOVA and post-hoc multiple comparisons can address the question what are the factors that affecting residents' preferences for conservation and livelihood trade-off at the community level. To answer this main question, we designed eight scenarios for community residents' ways of living and conservation optimization schemes according to previous household interviews, and we aimed to analyze all the factors at the community level. Although community residents are plan implementers and stakeholders, their perceptions of livelihoods in protected areas and preferences for optimizing protected areas are informative for policymakers to design extended policies and protect practices that enhance the sustainability of conservation outcomes [30]. 
In addition to the main question, for such a series of social-ecological transformation policies, we and local policymakers are also concerned about three sub-questions. What are the optimal regional livelihood solutions for Sanjiangyuan National Park? What are the real intentions of local residents? And what additional non-economic factors are related to these intentions? It is evident that the intentions and behaviors of farmers in protecting the ecology are closely related to their livelihoods and the outcome of protected area optimization programs [21]. In order to answer the questions above, this study aims to determine the factors affecting residents' preferences for protected areas and livelihood optimization strategies. In addition, this study is informative for farmers living in Sanjiangyuan National Park to adopt the expected exploration process based on the (ANOVA) method. Moreover, this study also provides information for decision makers to develop local economic expansion policies, design new nature reserves and approach other sustainable options in similar ways as the livelihoods and protected area optimization schemes designed in this study.

\section{Data and Analysis}

\subsection{Survey Data}

In total, 196 residents in Maduo and Zaduo counties in Sanjiangyuan National Park were visited and asked to fill in a standard questionnaire with regards to their tendencies to the optimization of livelihoods and conservation of the natural reserve. We implemented a random sampling over the registered households to survey the residents in Maduo and Zaduo counties. The survey was conducted during July and August 2018, and basic personal, socioeconomic and family information (including name, contact, address, gender, age, education level, annual family income, primary family income source, annual ecology compensation received by the family, primary ecology compensation type, residency length and whether moved in the national park or not after 2016) was collected in the beginning of the survey. Meanwhile, the awareness of ecology reserve, redline and compensation, visited the reserve or not, satisfaction of the surrounding ecology and environment, whether one believes that it necessary to improve ecology and the environment, satisfaction of the effects of present ecology and environment conservation, attitude to the tourism influence on ecology, and whether one believes that it necessary to develop tourism were surveyed for residents' awareness of and attitude towards ecology, environment, tourism and government policy. These factors were standard theory of planned behavior-based variables related to the local conditions in align with the interests of this study. For residents' tendencies to the optimization of livelihoods and conservation, 8 standard multiple-choice psychological questions were designed (Table A1) to explicitly examine their preferences for the land openness, land area for tourism development, relocation, guide of production from the government, and the amount of ecology compensation to be received. In addition to these questions, the confidence in the optimization policy and of ecology compensation were recorded, as well as their certainty while answering this questionnaire. Responses were checked for their completeness and validity before further analyses. Annual family income should be no less than annual ecology compensation received by the family; otherwise, the annual family income was marked incorrect and thus treated as NA. Awareness and satisfaction are coded in degree from negative to positive as $-2,-1$ to 1,2 , whereas neutral is 0 . 
The tendency of livelihoods and conservation policy was scored for each of the five categories (Table A1) following the approach applied commonly in other studies [35]. For each of the eight questions, different choices of degree and area of openness of reserve land, allocation and economic transformation of residents in the reserve land, and the amount of compensation consists of 3 scenarios, representing different tendencies. In all questions, the third scenario in each question is always to maintain the status quo, while the other two are contrasting changes in ecology conservation, tourism development, relocation and ecology compensation. Each choice is assigned a specific degree of openness reflecting the resident's tendency to their ideal livelihood and conservation plans, and, for each question, the difference between the first and second scenario is calculated for scoring the residents' openness of tendency if the resident's answer is the first or the second choice. If a resident's answer to a question is the third choice, for this question, he or she will receive a 0 score of openness. If not the third choice, this resident will receive the corresponding scores of openness for that question. Overall, all residents who answered at least 5 out of the 8 questions are scored, and their scores for each question are standardized before averaging all 8 questions to obtain the final scores of openness of tendency for these residents (for the detailed questions and openness scoring, please refer to Table A1). Therefore, these scaled answers are transformed in a standardized score for each resident surveyed.

\subsection{ANOVA}

After data preparation and variable standardization, the compiled dataset is used for conducting the hypothesized ANOVA tests. Explanatory variables are categorized into 4 groups, demographic and socioeconomic conditions of the residents, ecology compensation received, perception and awareness of ecology and environment conservation, confidence in livelihood and compensation policies, and the response variable is the tendency of livelihoods and conservation policy of natural reserve. Neutral responses are set as the reference levels for categorical explanatory variables where applicable. In the context of analysis, ANOVA with county always acting as a blocking effect is applied to analyze the variance of residents' tendency to livelihood and conservation for the effects of all the explanatory variables in each of the 4 groups, Significant variables in each group except for county are further analyzed using post hoc multiple comparisons based on least squares means with the Tukey method for $p$-value adjustment at the $95 \%$ confidence level. All the ANOVA and post hoc analyses above are completed using the R Version 3.5.1 and the lsmeans package [36].

\section{Results}

The ANOVA results are shown in Table 1 for the factors below: (1) demographic and socioeconomic conditions of the residents, (2) for ecology compensation received, (3) for perception and awareness of ecology and environment conservation and (4) for confidence in livelihood and compensation policies, all of which are against the tendency of livelihoods and conservation policy of natural reserve. Post-hoc multiple comparisons for significant terms in each explanatory variable group are summarized in Figure 1 and Table A2.

The county is always a useful blocking factor as it is significant in each ANOVA result. For demographic and socioeconomic conditions, only the primary income source has a significant impact on residents' tendency of livelihoods and conservation policy of natural reserve. Moreover, it is the source from government compensation that differs from ecology conservation manager. Notably, only the residents who chose the source from government compensation has a significant positive tendency compared to others' non-significant tendencies who chose the other three sources. For ecology compensation received, neither the annual income from ecology compensation nor the compensation type matters. For the perception and awareness of ecology and environment conservation, awareness of ecology compensation, awareness of natural reserve, the score of ecology and environment conditions, perception of influence on ecology and the need for tourism development are significant factors. However, there is no significant differences among levels of awareness ecology compensation, nor levels of awareness of natural reserve. Very satisfactory (2) and not satisfactory 
$(-1)$ of the score of ecology and environment conditions are significantly different in terms of their corresponding tendencies. Not care (0) and positive perception (1) of influence on ecology are significantly different. Furthermore, all three levels of need for tourism development are significantly different from each other. However, only certain levels of these factors correspond to significant tendencies, as shown in Figure 1's multiple comparison parts. For the confidence in livelihood and compensation policies, only confidence in compensation policy has a significant impact on the tendency. Furthermore, the only significantly different pair is between strongly unconfident $(-2)$ and somehow unconfident $(-1)$, the former of which is the only level of confidence in compensation policy that has a significant corresponding positive tendency.

Table 1. ANOVA results for the impacts of four major factors on residents' tendencies.

\begin{tabular}{|c|c|c|c|c|}
\hline Factor & $\begin{array}{l}\text { Degrees of } \\
\text { Freedom }\end{array}$ & $\begin{array}{l}\text { Sum of } \\
\text { Squares }\end{array}$ & $\begin{array}{c}\text { F } \\
\text { Value }\end{array}$ & Significance \\
\hline \multicolumn{5}{|l|}{ Demographic and Socioeconomic Conditions } \\
\hline County & 1 & 2.151 & 12.27 & $* * *$ \\
\hline Gender & 1 & 0.012 & 0.068 & ns \\
\hline Education Level & 4 & 0.392 & 0.558 & ns \\
\hline Annual Gross Income & 1 & 0.241 & 1.377 & ns \\
\hline Main Source of Income & 3 & 3.342 & 6.353 & $* * *$ \\
\hline Moved or Not & 1 & 0.002 & 0.013 & ns \\
\hline Residency Length & 1 & 0.054 & 0.307 & ns \\
\hline $\begin{array}{c}\text { Residuals for Demographic and Socioeconomic } \\
\text { Factors }\end{array}$ & 107 & 18.76 & & \\
\hline \multicolumn{5}{|l|}{ Amount and Type of Ecology Compensation } \\
\hline \multicolumn{5}{|l|}{ Received } \\
\hline County & 1 & 2.593 & 14.27 & $* * *$ \\
\hline Annual Ecology Income & 1 & 0.02 & 0.108 & ns \\
\hline Compensation Type & 4 & 0.888 & 1.222 & ns \\
\hline Residuals for Ecology Compensation Factors & 162 & 29.43 & & \\
\hline \multicolumn{5}{|l|}{ Perception and Awareness of Natural Conservation } \\
\hline County & 1 & 2.49 & 19.52 & $* * *$ \\
\hline Aware Ecology Redline Compensation & 4 & 1.599 & 3.135 & * \\
\hline Aware Natural Reserve & 4 & 1.601 & 3.138 & * \\
\hline Visited Reserve or Not & 1 & 0.02 & 0.156 & ns \\
\hline Visited Reserve Times & 1 & 0.144 & 1.126 & ns \\
\hline Score of Ecology Environment & 3 & 1.292 & 3.377 & * \\
\hline Need Improve of Ecology Environment & 2 & 0.207 & 0.813 & ns \\
\hline Score of Satisfaction of Government & 3 & 0.609 & 1.591 & ns \\
\hline Ecology Influence Perception & 2 & 1.002 & 3.926 & * \\
\hline Need Tourism Development & 2 & 2.904 & 11.38 & $* * *$ \\
\hline $\begin{array}{c}\text { Residuals for Perception and Awareness of Natural } \\
\text { Conservation Factors }\end{array}$ & 127 & 16.2 & & \\
\hline \multicolumn{5}{|l|}{ Confidence in Livelihood and Compensation Policies } \\
\hline County & 1 & 1.74 & 10.25 & $* *$ \\
\hline Confidence Policy & 4 & 1.107 & 1.63 & ns \\
\hline Confidence Compensation & 4 & 2.236 & 3.292 & * \\
\hline $\begin{array}{l}\text { Residuals for Confidence in Livelihood and } \\
\text { Compensation Policy Factors }\end{array}$ & 149 & 25.3 & & \\
\hline
\end{tabular}

Note: $\mathrm{ns}^{*}{ }^{* * *}$ and ${ }^{* * *}$ in Significance represent $p$-value of the $\mathrm{F}$ test as $p>0.05,0.05<p<0.01,0.01<p<0.001$, and $p<0.001$ respectively. 


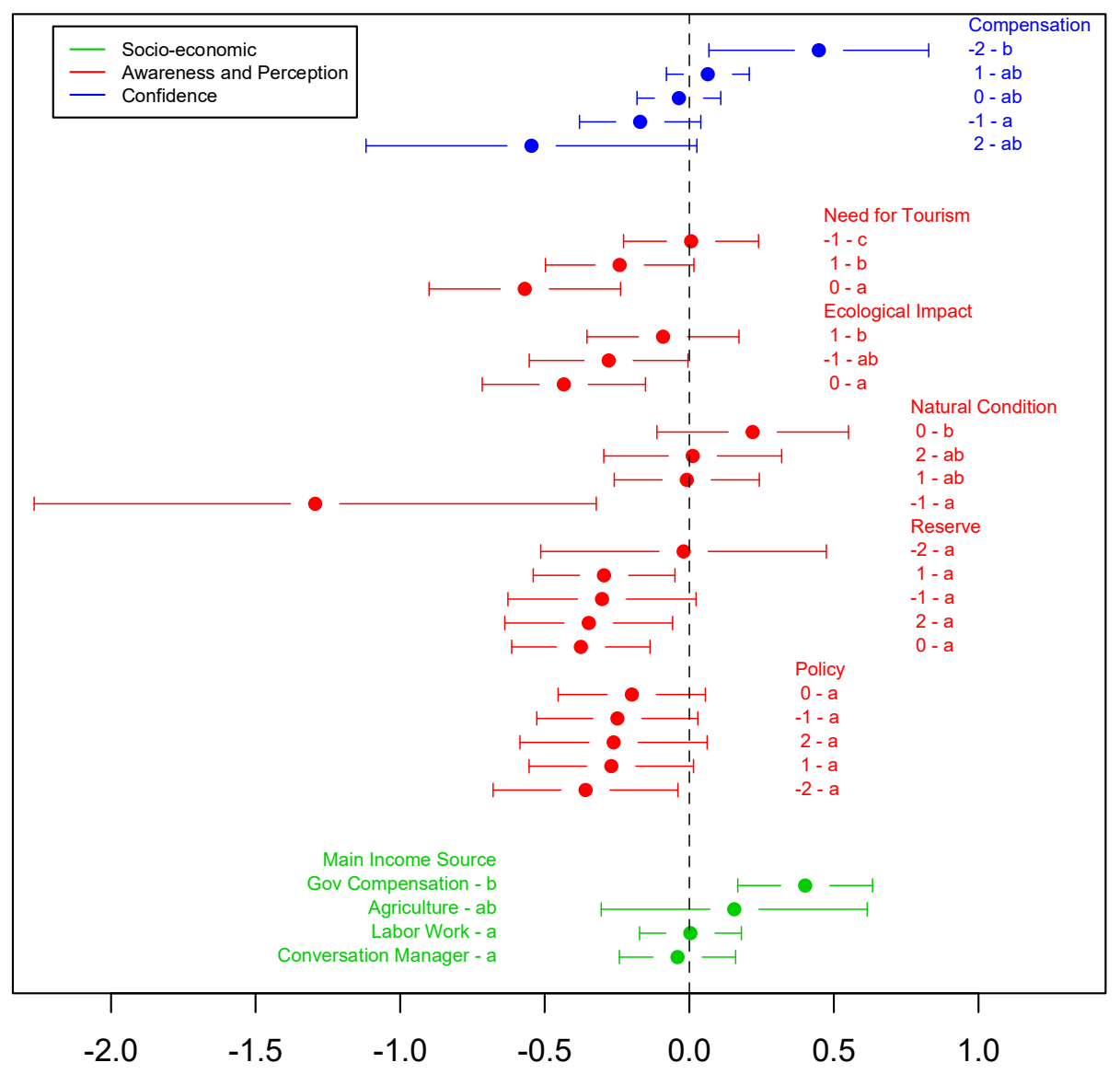

Least Square Mean Tendencies by Factors

Figure 1. In this figure, post hoc multiple comparisons for ANOVA results with significant $p$-values are shown by factors. The least square mean residents' tendencies to their optimized livelihood and conservation policy are displayed by significant ANOVA results in three groups, namely socio-economic, awareness and perception, and confidence in government groups. From bottom to top are the main income source (a socio-economic factor, in green color), awareness of conservation policy, awareness of natural reserve, score for natural condition, the perception of ecological impacts and the need for tourism development (five awareness and perception related factors, in red color), and the confidence of government compensation (a confidence in government factor, in blue color). The levels of each factor are specified in alignment with their 95\% confidence intervals of the mean tendencies (as the $x$-axis) for each level of the explanatory variables. Significantly different levels within each factor are marked using the post hoc marking scheme (e.g., a, is significantly different from b, but not from ab).

\section{Discussion}

4.1. Government Compensation as the Primary Economic Source Plays a Critical Role in Residents' Support for the Natural Reserve and Livelihood Optimization Programs

For the population and socio-economic situation (Table 1), only the main sources of income have a significant impact on the livelihood trends of residents and the conservation policies of nature reserves. Different from the person in charge of environmental protection is the source of government compensation. It is worth noting that only the residents who choose the source from the government compensation have an apparent positive trend, while residents choose the other three sources are found without significant positive tendencies. Strong impacts from government revenue were found associated with their inclination to trust the government, including local conservation policies, which was also evidenced during local family interviews during our survey. Their wealth has made them more open-minded, and they believe that "change" is worth trying. The present study addressed 
the concerns on the lack of feasible frameworks for exploring the farmers' tendentious behavior towards the livelihood mode and the reserve optimization scheme. Similarly, Beedell et al. [37] reported that the willingness of farmers greatly and positively influenced their protection behavior. Therefore, it is appropriate to use the wishes of farmers to reflect their expected behaviors. Edwards-Jones et al. [38] concluded that farmers' behavioral decisions are influenced by a variety of factors, including their socio-demography and the broader social environment. The advice of neighbors and family members, as well as the guidance of the government, affect the attitudes of farmers to protect ecological achievements. The findings show that proactive guidance and advocacy in the community can be used to improve farmers' attitude towards ecological protection. However, the direction is not defined. Naturally, farmers' views and interests in ecology may positively affect their attitudes towards ecological protection. To some extent, this impact will benefit farmers in their development of positive attitudes and lead to an easier understanding of ecological benefits [39]. In particular, farmers' intentions are influenced by personal and external perspectives and attitudes. The most influential factors are the pressure of their neighbors, followed by the government and family members. This finding, together with Gao et al.'s finding about neighborhood impacts on government trust [40], supports the external and internal influence variables of farmers' decision-making process [41]. Deng et al. [21] claims that the public can guide opinions in a positive direction through policy training and publicize them. Therefore, more extensive policy advocacy and interpretation must improve farmers' awareness of ecological protection.

\subsection{The Amount and Type of Ecological Compensation Have no Significant Impact on Residents' Preferences}

For the ecological compensation received (Table 1), the annual income and type of compensation for ecological compensation are not important to their preference. Conceptual things may not be very understandable. Because most of the residents' education level is limited, they cannot understand the professional terminology, such as ecological compensation (government financial support for contribution to ecological conservation) and ecology redline (the critical limit of ecological resource utilization in natural reserve), and they do not even wish to think about it, but this does not hinder their tendency of livelihood transformation into the new social ecology condition. However, it is worth noting that insufficient and biased information between the residents and local government may lead to the Prisoner's Dilemma devastating the trust bond between them [42]. This is expected as the variation of the amounts of ecological compensation received by different residents is not as large as the magnitude scale. And the types of ecological compensation have no direct relation to the actual amount of money that residents receive. One reason might be residents' doubt surrounding the justice, reasonability and fulfillment of government payment shift from central support to local compensation. In return, however, residents can only choose to believe in the promise that their local government made to stick with ecological compensation policies, but this mistrust will unfortunately enforce the local government to make their decisions less concerned about the residents, namely leading to the reverse selection effect [43]. Therefore, local government may maintain the range of the amount of ecological compensation eligible for the residents by applying all possible types of compensations to build up residents' tendencies to participate in natural conservation activities.

4.3. The Awareness of Policies and Natural Reserves, the Score of Environment Conditions, the Perception of Human Impacts, and the Demand for Tourism Are Four Important Factors Affecting Farmers' Tendency Also Related to Their Livelihoods

The understanding of ecological red line and ecological compensation, the understanding of natural protection, the rating of ecological and environmental conditions, the understanding of the ecological impact and the demand for tourism development (Table 1) are important factors. However, there is no significant difference in the level of understanding of ecological red line and ecological compensation and the level of the understanding of nature reserves. This is in terms of scores of ecological and environmental conditions. 
There are significant differences in the corresponding trends of very satisfied (2) and dissatisfied $(-1)$ (Figure 1). There is a significant difference between not caring $(0)$ and positive views on ecological impact (1) (Figure 1). Shuifa et al. [44] pointed out that, in most cases, farmers participating in the ecological restoration plan in China tend to assume rational (i.e., based on their abilities and needs) rather than emotional (i.e., based on likes or dislikes) behaviors when referring to their future plans, which are mainly based on personal abilities, family decision-making conditions, and cost and benefit estimation. This observation reasonably supports the importance of farmers' self-assessment and their ability to protect ecological achievements. This study also shows that the main factors that affect the residents' interests are significant, and the residents are most concerned about their interests. Allendorf el al. [32] found that resident attitudes and perceptions are important for management to understand how they can engage with local residents. Residents' perceptions can be used by management as a starting point to improve park-people relationships through feasible and targeted interventions that are meaningful to local communities and their relationships with a protected area. Understanding and acknowledging residents' perceptions is an important part of a process of engaging with local communities and building constructive relationships between residents and management.

Therefore, policymakers should pay more attention to improving farmers' views on ecological benefits, such as the living conditions and environment of rural communities are directly through the development of infrastructure. At the same time, it is necessary to enhance the ability of farmers to participate in ecological protection. Indeed, farmers' special skills have contributed to the lack of livelihood in Sanjiangyuan National Park. We suggest two ways to achieve this goal: to use the comprehensive regional development to help farmers increase their income and popularize the measures of farmers' vocational skills training to increase the efficiency and income of farmers' vocational skills production [45].

\subsection{Residents' Confidence in Livelihood and Compensation Policies Significantly Differ Along with the Positiveness of Their Tendencies}

For the confidence in livelihood and compensation policy (Table 1), only the confidence of compensation policy has a significant impact on the trend. The only significant difference is between a strong level of self-confidence (-2) and a level of self-confidence (-1) (Figure 1).

Confidence in livelihoods and compensation policies (Table 1), and only confidence in compensation policies can have a significant impact on this trend. The more they believe in policy, the more likely they are to change, and the government's influence in their minds will largely determine their continued trust in the future. If the government wants to handle the relationship between residents and policies better, it should give residents greater confidence and trust, and achieve win-win results, although the reseve selection may prevent the government from making such win-win effort, as Akerlof proposed [43]. This study shows that farmers' confidence in the existing compensation policies is the most effective factor in determining their support for the livelihood mode and the optimization scheme of the reserve. Colchester [46] found the similar social-ecological relationship in the British Columbia Conservation during the period of its national park establishment. However, in China's nature reserves, the implementation of ecological compensation policy, farmers can only get very little Living allowance [47]. At present, international laws recognize indigenous peoples' rights and new conservation policies accept that indigenous peoples may own and manage protected areas. Participatory field research shows that these new principles are not yet widely applied in Asia as national policies, laws and institutions have yet to be revised in conformity with international law. In this case, the government should pay more attention to the legislative concerns from the public and international organizations by ensuring the ecological conservation benefits for local residents [46]. 


\subsection{Geographic Heterogeneity is Always a Useful Blocking Factor, but There Are Certain Limitations in This Study}

It shows that the heterogeneous and the code are different in altitude, geographical location and ecosystem type, which leads to different results. However, due to our limitations, we could not accurately predict the specific causes of this problem in our research field. This study provides important insights on the use of the ANOVA method to explore the livelihood patterns of residents in the Sanjiangyuan National Park area and the optimization scheme of the reserve that affects the residents' tendentious factors. Even so, limitations should be noted in this study. First, it is difficult to measure the potential variables completely and accurately. Meijer et al. [48] reported that interviewees tend to answer questions in the following ways: being liked by others. Farmers' positive emotions may be exaggerated because they may have answered the following questions about what they think researchers want to hear [49]. This situation may lead to a more obvious social desirability bias, and ultimately to data bias. The issue is commonly encountered in urban planning studies and social surveys [50]. Response measures, including provisions for a more detailed description before the questionnaire project, and encouraging farmers to be honest, have been implemented to reduce this bias so as we did in this study. Another limitation during the period of considering data analysis is the lack of socio-economic factors. Although the process is well explained on the basis of psychosocial factors, the socio-economic and personal characteristics of farmers play an important role in determining their social cognition and attitudes [51]. Therefore, future research should consider other factors to obtain more valuable information and enhance individual's understanding of the design proportion of residents' livelihood mode so as to reserve optimization scheme.

\section{Conclusions}

The complex and context-specific relationship between the livelihoods of residents in the national park and the natural protection poses many challenges to national park management. Although a long-term interdisciplinary approach may be required to fully understand the relationship between the environment and people in a particular national park, the reality is that most national park management decisions are made by people working in protected areas. One potential entry point for management to understand the relationship between parks and people and to improve management is through studying local people's understanding of a national park.

In this paper, the ANOVA results differentiate the impacts of tendentious factors of farmers for their livelihood modes and the optimization scheme to conserve nature reserves. In the Sanjiangyuan National Park area, the analysis and framework provided here may be very useful for considering the broader scales of the social-ecological transformation and the political aspects in this social-ecological phenomenon. The results answer the main question of this study by implying that factors from government income make residents more inclined to believe in the local government while wealth makes them more open, and it is worth trying to accept "change" from residents' perceptions. It is also evident that by increasing the income from government compensations, residents are more willing to accept the government's new policy measures. As for the three sub-questions of this study, results are informative from three aspects. Firstly, it is found that due to the limitation of the education level, most residents cannot understand the professional terms (such as ecological compensation, ecological red line, etc., that residents do not understand), the conceptual provisions may not be easy for them to understand. As a matter of fact, the residents did not consider the terms and conditions, but this situation did not hinder the government from implementing the new policy trend. To solve this conflict, the government can invite the residents to spread the professional terms about the government compensation policy so as to improve the residents' awareness of the government policy. Secondly, the residents' comparative support for policies and measures is closely related to their interests. However, due to the heterogeneity of geography and society, the level of support among different counties is different. In future studies, it is advised to expand the research scale to residents' livelihood mode and the inclination of the optimization plan of the nature reserve, and it is also necessary to study the specific natural geographical factors that affect this tendency. Thirdly, residents 
who have confidence in government policies are more likely to have confidence in future government plans. Though expected, this result brings the local residential confidence in the government into consideration for national park management and ecological conservation [52].

The resulting conflict, compatibility, or complementarity between the demands created by livelihood activities and conservation objectives have been the focal point of much discussion over the last two decades. There has been considerable debate as to the effectiveness of Integrated Conservation and Development Projects that, as the name implies, seek to link conservation and livelihood objectives $[28,29]$. We contribute to analyzing the factors that are affecting residents' preferences for conservation and livelihood trade-off at the community level [30], which is likely to be helpful in addressing similar issues in other Chinese and international contexts.

Residents' views can be used by management as a starting point for improving the relationship between parks and people through feasible and targeted interventions that are meaningful to the local community and its relationship with protected areas. We believe that the results of our paper can provide informative results and implications for people from neighboring countries, other developing countries, and world conservation organizations.

Author Contributions: Conceptualization, T.M.; Data curation, T.M. and K.X.; Formal analysis, T.M.; Funding acquisition, W.S.; Investigation, T.M., Y.X. and H.S.; Methodology, K.X.; Project administration, T.M.; Supervision, W.S.; Validation, W.S.; Writing—original draft, T.M.; Writing—review \& editing, T.M., and W.S. All authors have read and agreed to the published version of the manuscript.

Funding: This work was supported by National Key Research and Development Program (2017YFC0506501).

Acknowledgments: We wish to thank the Sanjiangyuan national park administration for their devoted contribution to the study. In addition, thank you to the government staff of Lancangjiang national park management committee for supplying informational material to participants of the study and Yonghong Mou for his thoughtful input and valuable suggestions.

Conflicts of Interest: The authors declare no conflict of interest. 


\section{Appendix A}

Table A1. The 8 Psychological Questions for the Preference for Livelihood Reformation Strategies $\left(1 \mathrm{Mu}=666.67 \mathrm{~m}^{2}\right)$.

\begin{tabular}{|c|c|c|c|}
\hline Question 1 & Choice A & Choice B & Choice C \\
\hline Degree of Openness of Reserve Land & Fully closed (-2) & Fully closed (-2) & Maintain the status quo \\
\hline Area of Openness of Reserve Land & Reduce by $10 \%(-1)$ & Reduce by $10 \%(-1)$ & Maintain the status quo \\
\hline Allocation of Residents in the Reserve Land & Allocation by group moving $(+1)$ & Allocation by group moving $(+1)$ & Maintain the status quo \\
\hline Economic Transformation of Residents in the Reserve Land & Economic crops $(-2)$ & Labor work $(+2)$ & Maintain the status quo \\
\hline Amount of Compensation (RMB per 100 Mu per Year) & $100(+1)$ & $500(+5)$ & Maintain the status quo \\
\hline Question 2 & Choice A & Choice B & Choice C \\
\hline Degree of Openness of Reserve Land & Interactive tourism $(+1.5)$ & Fully developed $(+2)$ & Maintain the status quo \\
\hline Area of Openness of Reserve Land & Reduce by $10 \%(-1)$ & Reduce by $10 \%(-1)$ & Maintain the status quo \\
\hline Allocation of Residents in the Reserve Land & Allocation in the original place $(0)$ & Allocation by group moving $(+1)$ & Maintain the status quo \\
\hline Economic Transformation of Residents in the Reserve Land & Village tourism $(+1)$ & Labor work $(+2)$ & Maintain the status quo \\
\hline Amount of Compensation (RMB per $100 \mathrm{Mu}$ per Year) & $100(+1)$ & $100(+1)$ & Maintain the status quo \\
\hline Question 3 & Choice A & Choice B & Choice C \\
\hline Degree of Openness of Reserve Land & Sightseeing tourism $(+1)$ & Sightseeing tourism $(+1)$ & Maintain the status quo \\
\hline Area of Openness of Reserve Land & Reduce by $10 \%(-1)$ & Increase by $10 \%(+1)$ & Maintain the status quo \\
\hline Allocation of Residents in the Reserve Land & Allocation by group moving $(+1)$ & Allocation in the original place $(0)$ & Maintain the status quo \\
\hline Economic Transformation of Residents in the Reserve Land & Labor work $(+2)$ & Labor work $(+2)$ & Maintain the status quo \\
\hline Amount of Compensation (RMB per 100 Mu per Year) & $100(+1)$ & $100(+1)$ & Maintain the status quo \\
\hline Question 4 & Choice A & Choice B & Choice C \\
\hline Degree of Openness of Reserve Land & Sightseeing tourism $(+1)$ & Fully developed $(+2)$ & Maintain the status quo \\
\hline Area of Openness of Reserve Land & Increase by $10 \%(+1)$ & Reduce by $10 \%(-1)$ & Maintain the status quo \\
\hline Allocation of Residents in the Reserve Land & Allocation in the original place $(0)$ & Allocation in the original place $(0)$ & Maintain the status quo \\
\hline Economic Transformation of Residents in the Reserve Land & Economic crops $(-2)$ & Ecology conservation manager $(0)$ & Maintain the status quo \\
\hline Amount of Compensation (RMB per 100 Mu per Year) & $500(+5)$ & $500(+5)$ & Maintain the status quo \\
\hline Question 5 & Choice A & Choice B & Choice C \\
\hline Degree of Openness of Reserve Land & Interactive tourism $(+1.5)$ & Interactive tourism $(+1.5)$ & Maintain the status quo \\
\hline Area of Openness of Reserve Land & Reduce by $10 \%(-1)$ & Increase by $10 \%(+1)$ & Maintain the status quo \\
\hline Allocation of Residents in the Reserve Land & Allocation in the original place $(0)$ & Allocation by group moving $(+1)$ & Maintain the status quo \\
\hline Economic Transformation of Residents in the Reserve Land & Economic crops $(-2)$ & Village tourism $(+1)$ & Maintain the status quo \\
\hline Amount of Compensation (RMB per 100 Mu per Year) & $100(+1)$ & $500(+5)$ & Maintain the status quo \\
\hline
\end{tabular}


Table A1. Cont.

\begin{tabular}{|c|c|c|c|}
\hline Question 1 & Choice A & Choice B & Choice C \\
\hline Question 6 & Choice A & Choice B & Choice C \\
\hline Degree of Openness of Reserve Land & Fully closed (-2) & Fully developed (+2) & Maintain the status quo \\
\hline Area of Openness of Reserve Land & Reduce by $10 \%(-1)$ & Reduce by $10 \%(-1)$ & Maintain the status quo \\
\hline Allocation of Residents in the Reserve Land & Allocation in the original place $(0)$ & Allocation in the original place $(0)$ & Maintain the status quo \\
\hline Economic Transformation of Residents in the Reserve Land & Ecology conservation manager $(0)$ & Village tourism $(+1)$ & Maintain the status quo \\
\hline Amount of Compensation (RMB per $100 \mathrm{Mu}$ per Year) & $100(+1)$ & $100(+1)$ & Maintain the status quo \\
\hline Question 7 & Choice A & Choice B & Choice C \\
\hline Degree of Openness of Reserve Land & Interactive tourism $(+1.5)$ & Fully developed $(+2)$ & Maintain the status quo \\
\hline Area of Openness of Reserve Land & Reduce by $10 \%(-1)$ & Reduce by $10 \%(-1)$ & Maintain the status quo \\
\hline Allocation of Residents in the Reserve Land & Allocation by group moving $(+1)$ & Allocation by group moving $(+1)$ & Maintain the status quo \\
\hline Economic Transformation of Residents in the Reserve Land & Ecology conservation manager $(0)$ & Economic crops $(-2)$ & Maintain the status quo \\
\hline Amount of Compensation (RMB per $100 \mathrm{Mu}$ per Year) & $100(+1)$ & $1000(+10)$ & Maintain the status quo \\
\hline Question 8 & Choice A & Choice B & Choice C \\
\hline Degree of Openness of Reserve Land & Sightseeing tourism $(+1)$ & Fully closed $(-2)$ & Maintain the status quo \\
\hline Area of Openness of Reserve Land & Reduce by $10 \%(-1)$ & Increase by $10 \%(+1)$ & Maintain the status quo \\
\hline Allocation of Residents in the Reserve Land & Allocation by group moving $(+1)$ & Allocation in the original place $(0)$ & Maintain the status quo \\
\hline Economic Transformation of Residents in the Reserve Land & Ecology conservation manager $(0)$ & Village tourism $(+1)$ & Maintain the status quo \\
\hline Amount of Compensation (RMB per $100 \mathrm{Mu}$ per Year) & $100(+1)$ & $500(+5)$ & Maintain the status quo \\
\hline
\end{tabular}


Table A2. Multiple comparison results for ANOVA on the source of main income, the type and amount of ecology compensation received, the perception and awareness of ecology and environment conservation, and the confidence in livelihood and compensation policies.

\begin{tabular}{|c|c|c|c|}
\hline \multicolumn{4}{|c|}{ Multiple Comparison for Main Income Source } \\
\hline Main Income Source & Least Square Mean & $\begin{array}{l}\text { Standard Error } \\
\text { (Significance) }\end{array}$ & Group \\
\hline Ecology Conservation Manager & -0.0407 & 0.1026 & 1 \\
\hline Labor & 0.0038 & 0.0898 & 1 \\
\hline Agriculture & 0.1554 & 0.2347 & 12 \\
\hline Government Compensation & 0.4008 & $0.1189 * * *$ & 2 \\
\hline \multicolumn{4}{|c|}{ Multiple comparison for awareness of ecology redline and ecology compensation } \\
\hline $\begin{array}{l}\text { Aware Ecology Redline } \\
\text { Compensation }\end{array}$ & Least Square Mean & $\begin{array}{l}\text { Standard Error } \\
\text { (Significance) }\end{array}$ & Group \\
\hline-2 & -0.359 & $0.163 *$ & 1 \\
\hline 1 & -0.270 & 0.145 & 1 \\
\hline 2 & -0.262 & 0.165 & 1 \\
\hline-1 & -0.249 & 0.142 & 1 \\
\hline 0 & -0.199 & 0.130 & 1 \\
\hline \multicolumn{4}{|c|}{ Multiple comparison for awareness of natural reserve } \\
\hline Aware Natural Reserve & Least Square Mean & $\begin{array}{l}\text { Standard Error } \\
\text { (Significance) }\end{array}$ & Group \\
\hline 0 & -0.375 & $0.122 * * *$ & 1 \\
\hline 2 & -0.348 & $0.148 *$ & 1 \\
\hline-1 & -0.302 & 0.166 & 1 \\
\hline 1 & -0.295 & 0.125 * & 1 \\
\hline-2 & -0.020 & 0.252 & 1 \\
\hline \multicolumn{4}{|c|}{ Multiple comparison for score of ecology and environment conditions } \\
\hline Score of Ecology Environment & Least Square Mean & $\begin{array}{l}\text { Standard Error } \\
\text { (Significance) }\end{array}$ & Group \\
\hline-1 & -1.294 & $0.496^{* *}$ & 1 \\
\hline 1 & -0.009 & 0.128 & 12 \\
\hline 2 & 0.012 & 0.157 & 12 \\
\hline 0 & 0.219 & 0.169 & 2 \\
\hline \multicolumn{4}{|c|}{ Multiple comparison for perception of influence on ecology } \\
\hline Ecology Influence Perception & Least Square Mean & $\begin{array}{l}\text { Standard Error } \\
\text { (Significance) }\end{array}$ & Group \\
\hline 0 & -0.434 & $0.144^{* * *}$ & 1 \\
\hline-1 & -0.279 & 0.140 * & 12 \\
\hline 1 & -0.091 & 0.134 & 2 \\
\hline \multicolumn{4}{|c|}{ Multiple comparison for need of tourism development } \\
\hline Need Tourism Development & Least Square Mean & $\begin{array}{l}\text { Standard Error } \\
\text { (Significance) }\end{array}$ & Group \\
\hline 0 & -0.569 & $0.169 * * *$ & 1 \\
\hline 1 & -0.241 & 0.131 & 2 \\
\hline-1 & 0.006 & 0.119 & 3 \\
\hline \multicolumn{4}{|c|}{ Multiple comparison for confidence in compensation } \\
\hline Confidence Compensation & Least Square Mean & $\begin{array}{l}\text { Standard Error } \\
\text { (Significance) }\end{array}$ & Group \\
\hline 2 & -0.546 & 0.292 & 12 \\
\hline-1 & -0.170 & 0.107 & 1 \\
\hline 0 & -0.036 & 0.074 & 12 \\
\hline 1 & 0.064 & 0.073 & 12 \\
\hline-2 & 0.448 & 0.194 * & 2 \\
\hline
\end{tabular}




\section{References}

1. Turnhout, E.; Neves, K.; De Lijster, E. 'Measurementality' in biodiversity governance: Knowledge, transparency, and the Intergovernmental Science-Policy Platform on Biodiversity and Ecosystem Services (IPBES). Environ. Plan. A 2014, 46, 581-597. [CrossRef]

2. Mastrángelo, M.E.; Pérez-Harguindeguy, N.; Enrico, L.; Bennett, E.; Lavorel, S.; Cumming, G.S.; Abeygunawardane, D.; Amarilla, L.D.; Burkhard, B.; Egoh, B.N. Key knowledge gaps to achieve global sustainability goals. Nat. Sustain. 2019, 2, 1115-1121. [CrossRef]

3. Cardillo, E.; Longo, M.C. Managerial Reporting Tools for Social Sustainability: Insights from a Local Government Experience. Sustainability 2020, 12, 3675. [CrossRef]

4. Zhou, D.Q.; Grumbine, R.E. National parks in China: Experiments with protecting nature and human livelihoods in Yunnan province, Peoples' Republic of China (PRC). Biol. Conserv. 2011, 144, 1314-1321. [CrossRef]

5. Wang, J.Z. National parks in China: Parks for people or for the nation? Land Use Policy 2019, 81, 825-833. [CrossRef]

6. Cheng, G.; Jin, H. Permafrost and groundwater on the Qinghai-Tibet Plateau and in northeast China. Hydrogeol. J. 2013, 21, 5-23. [CrossRef]

7. Huang, X.; Deng, J.; Wang, W.; Feng, Q.; Liang, T. Impact of climate and elevation on snow cover using integrated remote sensing snow products in Tibetan Plateau. Remote Sens. Environ. 2017, 190, $274-288$. [CrossRef]

8. Wu, J.; Wu, G.; Zheng, T.; Zhang, X.; Zhou, K. Value capture mechanisms, transaction costs, and heritage conservation: A case study of Sanjiangyuan National Park, China. Land Use Policy 2020, 90, 104246. [CrossRef]

9. Liu, Y.; Weckworth, B.; Li, J.; Xiao, L.; Zhao, X.; Lu, Z. China: The Tibetan Plateau, Sanjiangyuan Region. In Snow Leopards; Elsevier: Amsterdam, The Netherlands, 2016; pp. 513-521.

10. Foggin, J.M.; Torrance-Foggin, M.E. How can social and environmental services be provided for mobile Tibetan herders? Collaborative examples from Qinghai Province, China. Pastor. Res. Policy Pract. 2011, 1, 21. [CrossRef]

11. Li, X.L.; Gao, J.; Brierley, G.; Qiao, Y.M.; Zhang, J.; Yang, Y.W. Rangeland degradation on the Qinghai-Tibet plateau: Implications for rehabilitation. Land Degrad. Dev. 2013, 24, 72-80. [CrossRef]

12. Zhou, H.; Zhao, X.; Tang, Y.; Gu, S.; Zhou, L. Alpine grassland degradation and its control in the source region of the Yangtze and Yellow Rivers, China. Grassl. Sci. 2005, 51, 191-203. [CrossRef]

13. Liu, Y.; Gupta, H.; Springer, E.; Wagener, T. Linking science with environmental decision making: Experiences from an integrated modeling approach to supporting sustainable water resources management. Environ. Model. Softw. 2008, 23, 846-858. [CrossRef]

14. Sheng, W.; Zhen, L.; Xiao, Y.; Hu, Y. Ecological and socioeconomic effects of ecological restoration in China's Three Rivers Source Region. Sci. Total Environ. 2019, 650, 2307-2313. [CrossRef]

15. Liu, H.; Willems, P.; Bao, A.; Wang, L.; Chen, X. Effect of climate change on the vulnerability of a socio-ecological system in an arid area. Glob. Planet Chang. 2016, 137, 1-9. [CrossRef]

16. Wu, Z.; Wu, J.; Liu, J.; He, B.; Lei, T.; Wang, Q. Increasing terrestrial vegetation activity of ecological restoration program in the Beijing-Tianjin Sand Source Region of China. Ecol. Eng. 2013, 52, 37-50. [CrossRef]

17. Cao, S.; Xu, C.; Chen, L.; Wang, X. Attitudes of farmers in China's northern Shaanxi Province towards the land-use changes required under the Grain for Green Project, and implications for the project's success. Land Use Policy 2009, 26, 1182-1194. [CrossRef]

18. Bo, N.; Ning, M.; Houqiang, Z.; Li, H. Empirical analysis on the influencing factors of farmer Households' willingness of maintaining the results of the conversion of cropland to forestland program in Western China. For. Econ. 2014, 4, 13.

19. Wang, S.H.; Zhi, L.; Zhang, Y. The research analysis about the choose of farmers' rehabilitation in the later of returning land from farming to forestry-cases study of Anding District in Gansu Province. Issues For. Econ. 2010, 30, 478-481.

20. Yang, X.; Xu, J. Program sustainability and the determinants of farmers' self-predicted post-program land use decisions: Evidence from the Sloping Land Conversion Program (SLCP) in China. Environ. Dev. Econ. 2014, 19, 30-47. [CrossRef] 
21. Deng, J.; Sun, P.; Zhao, F.; Han, X.; Yang, G.; Feng, Y. Analysis of the ecological conservation behavior of farmers in payment for ecosystem service programs in eco-environmentally fragile areas using social psychology models. Sci. Total Environ. 2016, 550, 382-390. [CrossRef]

22. Knowler, D.; Bradshaw, B. Farmers' adoption of conservation agriculture: A review and synthesis of recent research. Food Policy 2007, 32, 25-48. [CrossRef]

23. Borges, J.A.R.; Lansink, A.G.O.; Ribeiro, C.M.; Lutke, V. Understanding farmers' intention to adopt improved natural grassland using the theory of planned behavior. Livest. Sci. 2014, 169, 163-174. [CrossRef]

24. Wauters, E.; Mathijs, E. An investigation into the socio-psychological determinants of farmers' conservation decisions: Method and implications for policy, extension and research. J. Agric. Educ. Ext. 2013, 19, 53-72. [CrossRef]

25. Poppenborg, P.; Koellner, T. Do attitudes toward ecosystem services determine agricultural land use practices? An analysis of farmers' decision-making in a South Korean watershed. Land Use Policy 2013, 31, 422-429. [CrossRef]

26. Truelove, H.B.; Carrico, A.R.; Thabrew, L. A socio-psychological model for analyzing climate change adaptation: A case study of Sri Lankan paddy farmers. Glob. Environ. Chang. 2015, 31, 85-97. [CrossRef]

27. Yazdanpanah, M.; Hayati, D.; Hochrainer-Stigler, S.; Zamani, G.H. Understanding farmers' intention and behavior regarding water conservation in the Middle-East and North Africa: A case study in Iran. J. Environ. Manag. 2014, 135, 63-72. [CrossRef]

28. Brandon, K.E.; Wells, M. Planning for people and parks: Design dilemmas. World Dev. 1992, $20,557-570$. [CrossRef]

29. Western, M.; Wright, E.O. The permeability of class boundaries to intergenerational mobility among men in the United States, Canada, Norway and Sweden. Am. Sociol. Rev. 1994, 606-629. [CrossRef]

30. Salafsky, N.; Wollenberg, E. Linking livelihoods and conservation: A conceptual framework and scale for assessing the integration of human needs and biodiversity. World Dev. 2000, 28, 1421-1438. [CrossRef]

31. Peters, C.M.; Gentry, A.H.; Mendelsohn, R.O. Valuation of an Amazonian rainforest. Nature 1989, 339, $655-656$. [CrossRef]

32. Allendorf, T.D.; Aung, M.; Songer, M. Using residents' perceptions to improve park-people relationships in Chatthin Wildlife Sanctuary, Myanmar. J. Environ. Manag. 2012, 99, 36-43. [CrossRef]

33. Baird, T.D.; Leslie, P.W. Conservation as disturbance: Upheaval and livelihood diversification near Tarangire National Park, northern Tanzania. Glob. Environ. Chang. 2013, 23, 1131-1141. [CrossRef]

34. Gilbert, N. Agent-Based Models; Sage Publications: Thousand Oaks, CA, USA, 2019; p. 153.

35. Hood, R.W., Jr.; Hill, P.C.; Spilka, B. The Psychology of Religion: An Empirical Approach; Guilford Publications: New York, NY, USA, 2018; pp. 13-27.

36. R Core Team. R: A Language and Environment for Statistical Computing 2014; R Foundation for Statistical Computing: Vienna, Austria, 2015.

37. Beedell, J.; Rehman, T. Using social-psychology models to understand farmers' conservation behaviour. J. Rural Stud. 2000, 16, 117-127. [CrossRef]

38. Edwards-Jones, G. Modelling farmer decision-making: Concepts, progress and challenges. Anim. Sci. 2006, 82, 783-790. [CrossRef]

39. Fishbein, M.; Ajzen, I. Intention and Behavior: An Introduction to Theory and Research; Addison-Wesley: Reading, MA, USA, 1975; pp. 37-45.

40. Guo, H.; Li, B.; Hou, Y.; Lu, S.; Nan, B. Rural households' willingness to participate in the Grain for Green program again: A case study of Zhungeer, China. For. Policy Econ. 2014, 44, 42-49. [CrossRef]

41. Meijer, S.S.; Catacutan, D.; Sileshi, G.W.; Nieuwenhuis, M. Tree planting by smallholder farmers in Malawi: Using the theory of planned behaviour to examine the relationship between attitudes and behaviour. J. Environ. Psychol. 2015, 43, 1-12. [CrossRef]

42. Dawes, R.M.; McTavish, J.; Shaklee, H. Behavior, communication, and assumptions about other people's behavior in a commons dilemma situation. J. Pers. Soc. Psychol. 1977, 35, 1-11. [CrossRef]

43. Akerlof, G.A.; Milbourne, R.D. New calculations of income and interest elasticities in Tobin's model of the transactions demand for money. Rev. Econ. Stat. 1978, 60, 541-546. [CrossRef]

44. Shuifa, K. Farmer Household's Behavior of Conversion Cropland Based on Evolutionary Game Theory. For. Econ. 2007, 2. 
45. Roselli, L.; Casieri, A.; de Gennaro, B.C.; Sardaro, R.; Russo, G. Environmental and Economic Sustainability of Table Grape Production in Italy. Sustainability 2020, 12, 3670. [CrossRef]

46. Colchester, M. Conservation policy and indigenous peoples. Environ. Sci. Policy 2004, 7, 145-153. [CrossRef]

47. Sommer, U.; Forman-Rabinovici, A. The Politicization of Women's Health and Wellbeing. Sustainability 2020, 12, 3593. [CrossRef]

48. Oppenheim, A.N. Questionnaire Design, Interviewing and Attitude Measurement; Bloomsbury Publishing: London, UK, 2000; pp. 3-8.

49. Meijer, S.S.; Catacutan, D.; Ajayi, O.C.; Sileshi, G.W.; Nieuwenhuis, M. The role of knowledge, attitudes and perceptions in the uptake of agricultural and agroforestry innovations among smallholder farmers in sub-Saharan Africa. Int. J. Agric. Sustain. 2015, 13, 40-54. [CrossRef]

50. Ajzen, I. The Theory of Planned behaviour: Reactions and Reflections; Taylor \& Francis: Milton Park, UK, 2011.

51. Martínez-García, C.G.; Dorward, P.; Rehman, T. Factors influencing adoption of improved grassland management by small-scale dairy farmers in central Mexico and the implications for future research on smallholder adoption in developing countries. Livest. Sci. 2013, 152, 228-238. [CrossRef]

52. Tsetse, D.; De Groot, W.T. Opportunity and Problem in Context (OPiC): A Framework for Environmental Management. Sustainability 2009, 1, 19. [CrossRef]

(C) 2020 by the authors. Licensee MDPI, Basel, Switzerland. This article is an open access article distributed under the terms and conditions of the Creative Commons Attribution (CC BY) license (http://creativecommons.org/licenses/by/4.0/). 